but 9, Ir, I3, I5, I7, I9, 2I, 23, 25, 27, 29, 3r, 33, 35, 37 , and 39 may be most probably assigned to elements $34,36,44,48,50,50,54,54,60,64,66,66,70,70,76$, and 80 respectively. (The results for elements 34 , $36,50,54$, and 80 are Aston's.) If this be accepted, it follows that the differences $4 \mathrm{I}$ and 4.3 belong to element 82 , because $(a)$ the mass-number $20 x$ appears to be unstable (being the head of a series of unstable mass-numbers $20 \mathrm{I}, \mathrm{I} 57, \mathrm{II} 3,73$, and 33 ), and therefore $4 \mathrm{I}$ cannot be assigned to element 80 ; and $(b)$ because it is to be expected that element 82 , like 66 and 50 , has two odd isotopes. These are in consequence 205 and 207.

Of the six isotopes mentioned above, 206, 208, and 2 Io are end-products of radioactive series; possibly 207 is also; so that this analysis, if confirmed experimentally, cannot by itself claim to dispose of the view that common lead may be of radioactive origin. But neither does it necessarily support it; the matter is still left open.

It is not unlikely that the odd mass-number 205 is an isobare, because thallium $(z=8 \mathrm{I})$ is likely to consist of mass-numbers 203 and 205, not only because its atomic weight lies between these numbers but also from the analysis in my last letter. Aston, by showing that mercury has probably an isotope of 197 , first established the possibility of the existence of odd isobares in the inactive elements, since it is very probable that gold's principal isotope is I97 also. But, in general, odd isobares are likely to be rare among inactive elements, but not impossible, as I said.

Neodymium, dysprosium, and ytterbium were not mentioned in my last letter. The chief isotopes of the first of these appear to be $1_{42}, I_{44}, I_{45}$, and $1_{4} 6$, possibly $I_{4} 8$ and $I_{50}$ also; of the second, I60, I6I, $162,163,164$, and possibly 166 ; and of the third I72, I73, I74, I75, I76, and possibly I78. I should like also to make a few minor alterations to previous statements. Lanthanum is apparently not simple but includes (possibly very little of) I37; gold is not likely to have I99; holmium is mainly I65. Tellurium should contain I22. But as I have now been able to calculate simply both unstable mass-numbers and even isobares, details are not of first importance.

It is not asked that any of the mass-numbers of this or of the previous letter should be accepted before being disproved or confirmed by experiment. But they are of interest as being the most probable numbers obtained by a simple and straightforward consideration of the facts of radioactivity on the reasonable assumptions stated.

Dr. Lee's Laboratory, Christ Church,

A. S. Russell. Oxford, October I3.

\section{Problems of Hydrone and Water: the Origin of Electricity in Thunderstorms.}

Prof. Armstrong's friendly criticism (NATURE, October I3, p. 537) of my theory of the origin of electricity in thunderstorms seems to neglect the fact that my explanation of thunderstorms is based entirely upon experimental and observational evidence. If experiments can be said to prove anything, then my work and the work of others has shown conclusively that: $(a)$ if there are ascending currents exceeding 8 metres per second in the atmosphere, there must be a great deal of breaking of rain drops; (b) every time a water drop breaks there is a separation. of electricity; (c) the broken water drops retain a positive charge ; (d) the air attains a negative charge. On the other hand, observations have shown that there is a considerable excess of positive electricity brought down by rain. These are all tangible facts which any one can test by making the suitable experi- ments, and I have done nothing more than arrange them into such a form that a reasonable account of the phenomena of thunderstorms results.

Surely Prof. Armstrong does not wish to suggest that all this work is wrong because it does not fit in with his theory of hydrones. He cannot expect us to neglect the evidence that electricity is produced when drops break, because, according to his theory, it appears more likely that electricity would be produced when drops combine.

What alternative has he to offer to a theory which has met with very wide acceptance? He says : " Assuming that my interpretation be correct, may not the great rise in potential required to produce lightning have its origin in the coalescence or cooperation of minute drops charged by an external source?" This is very depressing, for it throws us back to where we were twenty years ago, with an unknown " external source" of electricity and erroneous ideas of the increase in the potential of a cloud due to the coalescence of the drops.

Meteorological Office, London.

$$
\text { G. C. Simpson. }
$$

\section{The Occurrence of Urease.}

LETTERS on the occurrence of urease are printed in NATURE of August II and September 22. In the former, Prof. Werner reports that he has found urease in all the leguminous nodular growths he has tested; in the latter, Prof. Beijerinck describes how he has detected the enzyme in $B$. radicicola. Prof. Werner writes: "So far as we have been able to ascertain, the peculiar root nodules of leguminous plants have not hitherto been tested for urease." I reproduce, therefore, the following passage from an article on "The Function of Hormones in regulating Metabolism," by my son and myself, published in the Annals of Botany, vol. xxv., No. xcviii., April I9II.

"Lastly, we may refer to the nodular growths on the roots of leguminous plants; these are known to be most essential to the proper growth of the plant but their function is by no means clear; it is well known that they are the seat of bacteroids and it may be that these function as assimilators of atmospheric nitrogen gas and convert it into ammonia; or it may be that they exercise digestive functions and serve to 'deamidate' amino-compounds. At all events, they are distinctly alkaline, whereas the root sap is acid. Moreover, it has been shown by Hutchinson and Miller, that, when distilled with magnesia under reduced pressure, the nodules furnish more ammonia than do the roots $\left(0^{\circ} 043\right.$ per cent. against 0.0I 6 per cent.). We suggest that some part at least of the influence exercised by the nodules may be due to their aminogenetic power. We propose to make this assumption the basis of experimental inquiry."

Then, I would direct attention to the British Association Report, Australia, I914, where, at p. Iog, the following passages are to be found, at the end of the Report of the Committee for the Study of Plant Enzymes.

"In view of the presence of ammonia in the nodular growths appearing on the roots of Leguminosæ, it appeared probable that the enzyme Urease would be found in these. It has been detected in the nodules from Lupins and a number of other Leguminosæ. Attempts to detect the enzyme in organisms cultivated from the nodules have thus far been attended with negative results.

"Mr. Benjamin, working at Hawkesbury Agricultural College, near Sydney, Australia, has detected urease in nodules from several Australian plants, including wattles; also on tubercles derived from the

$$
\text { NO. } 28 \text { I } 7 \text {, VOL. I I } 2]
$$

